\title{
Optimization of Flaxseed Oil Methyl Ester Synthesis Using Bio-alkaline Heterogenous Catalyst
}

\author{
${ }^{1}$ A.O. Etim, ${ }^{2}$ A.C. Eloka-Eboka and P. Musonge ${ }^{3}$
}

\begin{abstract}
The use of biological materials and mineral-rich waste resources as potential raw materials for biodiesel production is receiving lots of attention due to their eco-friendly and availability prospects. This study explored biodiesel production from flaxseed oil (FSO) through transesterification reaction catalysed by bio-alkali catalyst derived from banana peels. The process parameters (methanol to oil ratio, catalyst loading and reaction time) were designed and optimized via response surface methodology (RSM). The waste banana peels were dried and calcined to generate the bio-alkali solid catalyst, which was further characterised for its composition. The energy dispersive spectroscopy (EDS) showed that potassium is the key element present in the calcined ash. The significance of the developed quadratic model was ascertained by the analysis of variance (ANOVA) with the p-value outcome $(\mathrm{p}<0.05)$ and the coefficient of determination $\left(\mathrm{R}^{2}=0.9670\right)$ at $95 \%$ confidence level. Reaction time was found to have the most influential impact among the three parameters considered. At the optimum condition of reaction time of $51.42 \mathrm{~min}$, catalyst loading of $2.7 \mathrm{wt} \%$ and methanol to oil molar ratio of $11: 1$, the experimental yield was $96.50 \mathrm{wt} \%$ and the RSM predicted yield was 95.88 wt \%. The physicochemical properties (viscosity, density, cetane number, calorific value, iodine value and acid value) of flaxseed oil methyl ester (FSOME) were also analysed and compared with the international biodiesel standards. Results obtained confirm the viability of flax seed oil as another potential source of bioenergy.
\end{abstract}

Keywords: Biodiesel, bio-catalyst, flaxseed oil, transesterification, response surface methodology

\section{INTRODUCTION}

Fossil fuel is inadequate in supply due to the world's rapid increase in industrial exploitation and population growth. The

Manuscript received October 8, 2020.

This work was supported in part by the Durban University of Technology (DUT) through university research fund and the National Research Foundation of South Africa

A. Etim acknowledges the financial assistance by National Research Foundation - The World Academy of Sciences (NRF-TWAS), under grant number (110917) for this study.

A. O. Etim is with the Institute of Systems Science, Durban University of Technology, Durban, South Africa.

A.C. Eloka-Eboka is with the School of Chemical and Minerals Engineering, North West University, Potchefstroom, South Africa.

P. Musonge is with the Institute of Systems Science, Durban University of Technology, Durban, South Africa. upfront challenges on the environment due to the effect of combustion calls for urgent need for alternative fuels. Biodiesel among other biofuel options, emerge as green alternative source of energy with high combustion efficiency and less emission, reduced $\mathrm{CO}_{2}$, no sulphur impurities, are non-toxic, better lubricating property and safer storage. Additionally, biodiesel has a domestic background such that the raw materials can be sourced locally and used without any attendant constraint unlike fossil fuels that are limited and only available in some designated endowed areas.

Biodiesel, chemically referred to as fatty acid methyl ester (FAME) is produced from renewable biological sources such as vegetable oils, animal fats, waste oils and so on. Vegetable oils (edible and non-edible) such as sunflower, soybeans, jatropha, neem oil and others have been reported as potential oil sources for biodiesel production [1]-[4]. One of such vegetable oils among others is the flaxseed oil. Flaxseed is an annual dicotyledonous crop that belongs to Linaceae family. The seeds are oval in shape and about 4-6 cm long. Flaxseed is reported to contain a strategic fixed oil content of $30-40 \%$, which are mainly linoleic, oleic and linolenic acids [5]. Flaxseed is considered a drying oil which is mostly are used in varnishes and paint production.

Production of biodiesel is basically carried out via transesterification with homogenous or heterogenous catalysts (acid or base). Due to some characteristic problems, the use of homogenous catalysts are linked with soap formation, difficulties in separation, equipment corrosion and spent water hazard on the environment during transesterification. Heterogenous catalysts are preferred mostly those derived from biological sources in order to avert these problem. In recent research, waste agricultural base heterogenous catalysts are gaining increasing attention as the potential green catalyst in the production of biodiesel via transesterification approach. This is because they are renewable, available and highly effective [1], [6], [7]. Several agricultural waste materials and their potentials in biodiesel production has been reviewed and summarized by [8]. The characterization studies of waste banana peels ash revealed that potassium $(\mathrm{K})$ is the key elemental factor and is present in various forms of basic compounds such as $\mathrm{K}_{2} \mathrm{O}, \mathrm{KCl}$, $\mathrm{K}_{2} \mathrm{CO}_{3}$ [9] which enhances its catalytic activity in biodiesel production. 
Response surface methodology (RSM) has been deployed to replace one-factor at a time (OFAT) approach in evaluating the effect of parameters of production. RSM is effective in modelling and analysing the response as a function of all affecting parameters simultaneously. Improvement in evaluation of operating factors can be carried out using RSM with a reduced number of experiments. In this study, RSM was used to analyse and optimize the operating parameters in flaxseed oil methyl ester synthesis via transesterification approach. Although there are several studies on biodiesel production from flaxseed oil, reports regarding its synthesis using biocatalyst are not available. Therefore, this work seeks to investigate and evaluate the transesterification process using a bio-alkaline catalyst from banana peels. The properties of the produced FAME via this protocol were also evaluated to investigate its potential as an alternative fuel to petrol-diesel.

\section{MAterials AND MethodS}

\section{A. Chemicals}

All chemicals and reagents used in this study were of analytical grade and were deployed without further purification. These include methanol (98\% purity), ethanol (98\% purity), potassium hydroxide, potassium iodide, diethyl ether, monochloride solution, hydrochloric acid, phenolphthalein, cyclohexane and chloroform.

\section{B. Synthesis of bio-alkali catalyst}

The waste banana peels were washed thrice with distilled water and dried in the oven for $24 \mathrm{~h}$ at $80{ }^{\circ} \mathrm{C}$. The dried materials were ground to powder and sieved to obtain fine particle size of less than $50 \mathrm{~mm}$. The fine powder was further calcined in a muffle furnace at $700{ }^{\circ} \mathrm{C}$ for $4 \mathrm{~h}$. The calcined ash was pulverized with the aid of an agate mortar and pestle, and then packed into an air-tight container and was then used as a bio-alkaline catalyst without any further modification. The compositional analysis of the calcined ash were also performed using energy dispersive spectroscope (EDS) to determine the active element(s) present in the ash.

\section{EXPERIMENTAL DESIGN}

\section{A. Central composite design of the response surface methodology (RSM)}

Design of expert (DOE) software (11.1.0.1, Stat Ease Inc., Minneapolis, USA) was used for the design and statistical analysis of the data obtained in this study. Central composite design (CCD) adapted from the response surface methodology (RSM) was used to investigate the operational parameters and their synergy/interactive effects. A four level three factors design was used to generate 20 experimental runs. Table 1 shows the process input parameters to include methanol/oil molar ratio $(6: 1-14: 1)$, catalyst loading $(1.5-5.5 \mathrm{wt} \%)$ and reaction time $(40-80 \mathrm{~min})$. The CCD used comprises of 8 factorial experiments, 6 axial points and 6 centre points replicates to evaluate the pure error. The two extreme values $(-2$ and +2 ) acquired by CCD represent the lower and the upper values suggested by the software for all the parameters within the range studied. This was used to generate twenty experimental runs which are presented in the design matrix in Table 2 . The second order polynomial equation is given by the following Eq. (1)

$Y=\beta_{0}+\sum_{i=1}^{n} \beta_{i} X_{i}+\sum_{i=1}^{n} \beta_{i i} X_{i}^{2}+\sum_{i=1}^{n-1} \sum_{i=2}^{n} \beta_{i j} X_{i} X_{j}+h$

Where $\mathrm{Y}$ is the biodiesel yield, $\beta_{0}$ is the intercept, $\beta_{\mathrm{i}}$ is the first order coefficient, $\beta_{\mathrm{ii}}$ is the quadratic coefficient, $\beta_{\mathrm{ij}}$ is the interaction coefficient, $X_{\mathrm{i}}, X_{\mathrm{j}}$ are the coded values of the experimental preparation variables and $h$ is the random error. RSM was used to determine the regression and evaluate the equation of statistical significance. The data were fitted by the equation represented by Eq. (1) for the yield in terms of actual and predicted value of independence variables. To determine the significance of the process parameters, analysis of variance (ANOVA) and significance test at $95 \%$ confidence level were used. Both the regression equation and response surfaces were analyzed to obtain the optimal value for the chosen independent parameters. Other factors such as probability value $(P$-value), Fisher's test $\left(F\right.$-value), determination coefficient $\left(\mathrm{R}^{2}\right)$, the adjusted $R^{2}$ and predicted $R^{2}$ were also examined for predicting the responses. The actual and predicted values were plotted on a straight line in a normal probability plot to also evaluate the fit of the model.

TABLE I: FACTORS CONSIDERED BY CCD FOR THE TRANSESTERIFICATION OF FSO

\begin{tabular}{lcccccc}
\hline Factors & unit & \multicolumn{5}{c}{ Coded factor and levels } \\
& & -2 & -1 & 0 & 1 & 2 \\
\hline $\begin{array}{l}\text { Methanol/FS } \\
\begin{array}{l}\text { O molar ratio } \\
\text { Catalyst }\end{array}\end{array}$ & 6 & 8 & 10 & 12 & 14 \\
$\begin{array}{l}\text { loading } \\
\text { Reaction time }\end{array}$ & min & 40 & 50 & 60 & 70 & 80 \\
\hline
\end{tabular}

\section{EXPERIMENTAL PROCEDURE}

Transesterification was performed in a $250 \mathrm{ml}$ three-necked round bottom flask equipped with a thermometer to monitor the temperature of the reaction mixture and a water-cool condenser to reflux the evaporated methanol in order to maintain the constant ratio of methanol to oil throughout the reaction. The magnetic hot plate was used as a source of heat and agitation to enhance a uniform temperature and proper mixing of the reactants. Temperature of the reaction was maintained at $65{ }^{\circ} \mathrm{C}$ and a stirring speed of $800 \mathrm{rpm}$. The reaction was carried out at different set of parametric conditions according to the design matrix stipulated by CCD as shown in Table 2 . The flaxseed oil of specified quantity was discharged into the reactor and allowed to heat up to a desired temperature. Thereafter appropriate amount of methanol and catalyst were added and allowed to run according to the postulated reaction time provided in the design guide. After completion, the reaction mixture was transferred into the separating funnels and allowed for settling by gravitation for $12 \mathrm{~h}$, forming three layers (the crude biodiesel, glycerol and catalyst) arranged according to their density differences. The glycerol and catalyst layers were removed by decantation and the crude biodiesel layer was 
purified by washing with warm distilled water and heating to remove any traces of methanol, glycerol, catalyst and water. The purified Flaxseed seed oil methyl ester (FSOME) was subjected to fuel characterization for the physicochemical properties following the ASTM standards. The yield of FSOME produced was determined using Eq. 2:

FSOME yield $(\%)=\frac{\text { weight of FSOME produced }}{\text { weight of oil sample used }} \times 100$

\section{RESULTS AND DisCUSSION}

\section{A. Bio-alkaline catalyst characterization}

The characterization of bio-catalyst derived from waste banana products (such as peels, trunk and peduncle) has been studied [9]-[12]. The energy dispersive spectroscopy (EDS) results shows that the increasing order of compositions of the calcined ash is $\mathrm{K}>\mathrm{Cl}>\mathrm{Ca}>\mathrm{Si}>\mathrm{Mg}$, with $\mathrm{K}$ being the main contributing factor for its high activity (Table II).

TABLE II: ELEMENTAL COMPOSITIONS OF THE BIO-ALKALINE CATALYST

\begin{tabular}{ll}
\hline Element & \% mass fraction \\
\hline $\mathrm{K}$ & 44.25 \\
$\mathrm{Cl}$ & 8.67 \\
$\mathrm{Ca}$ & 2.46 \\
$\mathrm{Si}$ & 1.52 \\
$\mathrm{Mg}$ & 1.28 \\
$\mathrm{P}$ & 0.52 \\
$\mathrm{O}$ & 41.25 \\
\hline
\end{tabular}

\section{EXPERIMENTAL DESIGN AND STATISTICAL ANALYSIS}

The effect and interaction of the key operational parameters such as methanol to oil molar ratio, catalyst loading and reaction time on the transesterification process of flaxseed oil were examined using RSM. The central composite design (CCD) with three factors four levels was employed for modelling and optimization of the biodiesel production process as shown in Table 1. Twenty experimental runs were generated with one response (FSOME) which was successfully carried out according to the design matrix and the results are presented in Table III. The experimental runs were randomised to minimise the variability in the responses. The quadratic model was developed at $95 \%$ confidence level in order to predict the experimental results. The response model presented in Eq. (3), which include the coefficient of individual terms $\left(X_{1}, X_{2}\right.$ and $\left.\mathrm{X}_{3}\right)$, interactive terms $\left(\mathrm{X}_{1} \mathrm{X}_{2}, \mathrm{X}_{1} \mathrm{X}_{3}, \mathrm{X}_{2} \mathrm{X}_{3}\right)$ and quadratic terms $\left(\mathrm{X}_{1}^{2}, \mathrm{X}_{2}^{2}, \mathrm{X}_{3}^{2}\right)$.

$Y=94.98+0.5054 X_{1}-0.5162 X_{2}-0.9121 X_{3}-0.9875 X_{1} X_{2}+$

Eq. (3)

The significance of individual term, interaction and quadratic terms were determined by $F$-test and probability $p$-value. The consequent decreasing order of individual terms effect was $\mathrm{X}_{1}>$
$X_{3}>X_{2}$. The order of interaction effect was $X_{2} X_{3}>X_{1} X_{2}$. The interactive effect of $\mathrm{X}_{1} \mathrm{X}_{3}$ was not significant, therefore it was left out. The correlation between the actual experimental results and the predicted values are shown in Fig. 1. The obtained data were well fitted on the reduced quadratic model, which indicates that the model results were in a reasonable agreement with the experimental results within the design range.

The test of significance of the model was carried out by analysis of variance (ANOVA) and it is shown in Table IV. The F-value is used to determine the significance of the regression coefficients of the parameters. The F-value of 32.56 with a p-value of $<0.0001$ signifies that the model is significance [14]. There is only $0.01 \%$ chance that at F-value, this large number could occur due to noise. A reduced model is relevant in a case where the $p$-value is greater than 0.05 to simplify and improve the model for high prediction of regression coefficient $\left(\mathrm{R}^{2}\right)$ with a value close to 1 . Table $\mathrm{V}$ shows the fit statistics of the model, the adjusted $\mathrm{R}^{2}$ and the predicted $\mathrm{R}^{2}$ difference was less than 2 which indicates that they were in reasonable agreement. The precision ratio of 20.16 obtained was adequate and desirable to define the correlation between the operational parameters and the responses. The low coefficient of variance of less than $1 \%$ also confirms the predictive accuracy of the model. The parity plot that shows the correlation between the actual and predicted values is represented in Fig. 1 which also confirms the fit of the model.

TABLE III: EXPERIMENTAL MATRIX AND FSOME YIELDS FOR TRANSESTERIFICATION PROCESS

\begin{tabular}{|c|c|c|c|c|c|c|}
\hline \multirow{2}{*}{$\begin{array}{l}\begin{array}{l}\text { Std } \\
\text { order }\end{array} \\
\end{array}$} & \multirow{2}{*}{ Run } & \multicolumn{3}{|c|}{ Coded factors } & \multicolumn{2}{|c|}{ FSOME yield } \\
\hline & & $\mathrm{X}_{1}$ & $\mathrm{X}_{2}$ & $X_{3}$ & $\begin{array}{l}\text { FSOME } \\
\text { Yield } \\
(w t \%)\end{array}$ & $\begin{array}{l}\text { RSM } \\
\text { Predicted }\end{array}$ \\
\hline 11 & 1 & 0 & -2 & 0 & 93.15 & 93.60 \\
\hline 7 & 2 & -1 & 1 & 1 & 91.70 & 92.10 \\
\hline 6 & 3 & 1 & 1 & 1 & 93.95 & 93.89 \\
\hline 3 & 4 & -1 & -1 & -1 & 93.80 & 93.67 \\
\hline 10 & 5 & 1 & 1 & 0 & 93.50 & 93.86 \\
\hline 12 & 6 & 0 & 0 & 0 & 92.05 & 91.87 \\
\hline 9 & 7 & -2 & 0 & 0 & 92.25 & 92.16 \\
\hline 16 & 8 & 0 & 0 & 0 & 94.85 & 94.98 \\
\hline 20 & 9 & 0 & 0 & 0 & 95.20 & 94.98 \\
\hline 2 & 10 & 1 & 1 & -1 & 96.55 & 95.96 \\
\hline 4 & 11 & 1 & 1 & -1 & 92.10 & 92.13 \\
\hline 8 & 12 & 1 & 1 & 1 & 91.85 & 91.71 \\
\hline 19 & 13 & 0 & 0 & 0 & 94.70 & 94.98 \\
\hline 18 & 14 & 0 & 0 & 0 & 94.85 & 94.98 \\
\hline 1 & 15 & -1 & -1 & -1 & 93.60 & 93.55 \\
\hline 13 & 16 & 0 & 0 & 0 & 94.55 & 94.89 \\
\hline 17 & 17 & 0 & 0 & 0 & 95.51 & 94.98 \\
\hline 5 & 18 & -8 & -1 & -1 & 90.55 & 90.33 \\
\hline 14 & 19 & 0 & 0 & 0 & 91.90 & 91.83 \\
\hline 15 & 20 & 0 & 0 & 0 & 94.82 & 94.98 \\
\hline
\end{tabular}


TABLE IV: SIGNIFICANCE TEST OF ANOVA

\begin{tabular}{llllll}
\hline Source & $\begin{array}{l}\text { Sum of } \\
\text { Squares }\end{array}$ & df & $\begin{array}{l}\text { Mean } \\
\text { Square }\end{array}$ & F-value & p-value \\
\hline $\begin{array}{l}\text { Model } \\
\text { Methan } \\
\text { ol/oil }\end{array}$ & 45.77 & 9 & 5.09 & 32.56 & $<0.0001$ \\
loading & 3.49 & 1 & 3.49 & 22.33 & 0.0008 \\
$\left(\mathrm{X}_{1}\right)$ & & & & & \\
Catalyst & & & & & \\
Loading & 3.64 & 1 & 3.64 & 23.30 & 0.0007 \\
$\left(\mathrm{X}_{2}\right)$ & & & & & \\
Reactio & & & & & \\
$\mathrm{n}$ time & 11.36 & 1 & 11.36 & 72.74 & $<0.0001$ \\
$\left(\mathrm{X}_{3}\right)$ & & & & & \\
$\mathrm{X}_{1} \mathrm{X}_{2}$ & 7.80 & 1 & 7.80 & 49.94 & $<0.0001$ \\
$\mathrm{X}_{1} \mathrm{X}_{3}$ & 0.6613 & 1 & 0.6613 & 4.23 & 0.0667 \\
$\mathrm{X}_{2} \mathrm{X}_{3}$ & 1.36 & 1 & 1.36 & 8.71 & 0.0145 \\
$\mathrm{X}_{1}^{2}$ & 7.00 & 1 & 7.00 & 44.78 & $<0.0001$ \\
$\mathrm{X}_{2}^{2}$ & 9.08 & 1 & 9.08 & 58.16 & $<0.0001$ \\
$\mathrm{X}_{3}^{2}$ & 4.73 & 1 & 4.73 & 30.29 & 0.0003 \\
Residua & 1.56 & 10 & 0.1562 & & \\
I & & & & & \\
Lack of & 1.10 & 5 & 0.2191 & 2.35 & 0.1854 \\
Fit & & & & & \\
Pure & 0.4667 & 5 & 0.0933 & & \\
Error & & 19 & & & \\
Cor & 47.34 & & & & \\
Total & & & & & \\
\hline
\end{tabular}

\begin{tabular}{llll}
\multicolumn{4}{c}{ TABLE V: Fit Statistics OF THE Model } \\
\hline $\mathrm{R}^{2}$ & 0.9670 & Mean & 93.57 \\
${\text { Adjusted } \mathrm{R}^{2}}^{2}$ & 0.9373 & C.V. $\%$ & 0.4224 \\
Predicted $\mathrm{R}^{2}$ & 0.8021 & & \\
Adeq precision & 20.1638 & & \\
Standard Deviation & 0.3952 & & \\
\hline
\end{tabular}

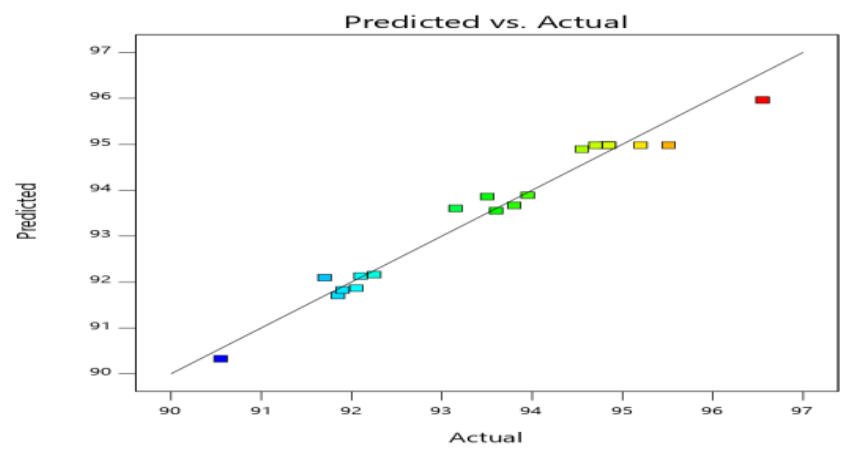

Fig.1: Parity plot of predicted versus actual values

\section{A. Interaction/effects of the process parameters on FSOME yield}

The 3D surface plot (Fig.2a) shows the impact of interaction of methanol to oil ratio $\left(\mathrm{X}_{1}\right)$ and reaction time $\left(\mathrm{X}_{3}\right)$ on FSOME yield while catalyst loading was held constant. The methanol/oil was studied by varying ratios from $6: 1$ to $14: 1$ and the reaction time from 40 to 80 mins while the catalyst $\left(\mathrm{X}_{2}\right)$ was kept constant at $2.7 \mathrm{wt} \%$. Of course, methanol to oil ratio is an essential factor in transesterification reaction. Increase in methanol/oil molar ratio and decrease time enhances significant increase in FSOME yield. At low ratio of methanol to oil and increasing time, the graph shows decrease of FSOME yield. This implies that excess methanol is needed to move the reaction towards the product formation in the transesterification of FSO. Reaction time is also an important parameter which allows for the reactant to have enough contact for the reaction to get to completion. Increase in FSOME was observed to increase at low reaction time and reaches maximum at $40 \mathrm{~min}$. The $p$-value in Table 4, shows that both terms are significant but the impact of reaction time $(p<0.0001)$ is stronger than methanol to oil ratio ( $\mathrm{p}$-value $<0.0008$ ). similar trend has also been reported by [15].

The effect of interaction between the catalyst and reaction time while methanol was kept constant is also presented in Fig. 2b. In order to speed up the rate of the transesterification reaction, effective catalyst is required. The catalyst loading levels were investigated from $1.5-5.5 \mathrm{wt} \%$. It was observed that FSOME yield increases at low catalyst weight and short reaction time between 1.5 to $3 \mathrm{wt} \%$ catalyst loading and $40-60 \mathrm{~min}$. The optimal FOSME yield was achieved at catalyst weight of $2.7 \%$ and the reaction time of $51.42 \mathrm{~min}$.

\section{TRANSESTERIFICATION PROCESS PARAMETER OPTIMIZATION}

To ascertain the optimal condition in order to maximise yields, numerical optimization tool of the software (DOE) was used based on experimental result. This was achieved by setting the FSOME yield at maximum of $100 \%$ and selecting the independent variables within the range studied (Fig.3). The software predicted the yield of $95.88 \mathrm{wt} \%$ at the desirability of $82 \%$, at the optimal process condition of methanol to oil ratio of 11 , catalyst loading of $2.7 \mathrm{wt} \%$ and the reaction time of 51.41 min. Additional experiments were conducted thrice to validate the software prediction based on the above condition. The percentage FSOME yield was determined using Eq.2 and the average was observed at $96.50 \mathrm{wt} \%$. Comparing the predicted and experimental results, it was construed that the deviation between them was less than $1 \%$, indicating that the model predicted results are well aligned with the experimental data. Hence this shows that the model is accurate and coupled with the low optimal parametric condition values predicted with high yield, it can be adapted for an economical biodiesel production process.

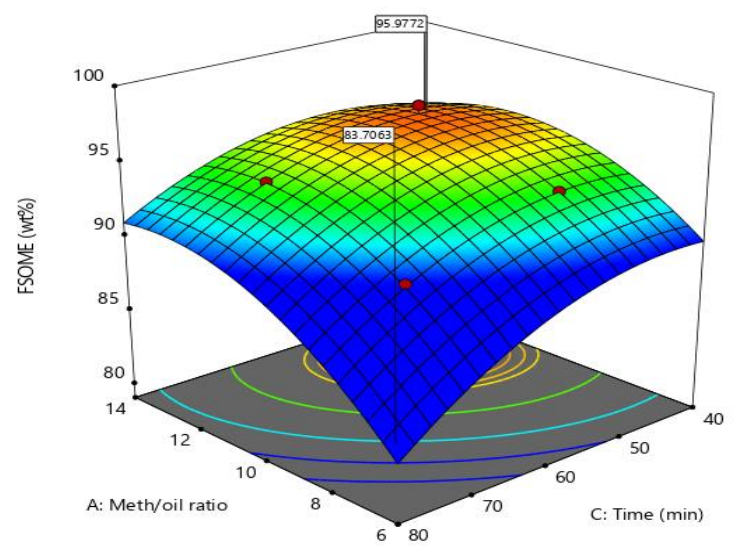

(a) 


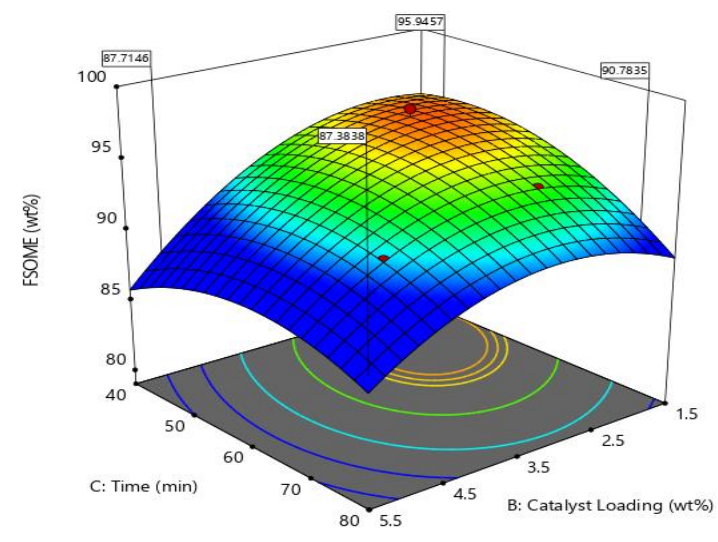

(b)

Fig. 2: Plot of significance and model fit in FSOME synthesis

\section{PHYSICOCHEMICAL PROPERTIES OF FSOME}

The major properties of flaxseed oil methyl ester namely: density, viscosity, acid value, heating value, iodine value, cetane number were measured using standard method and compared with ASTM D 6751 and EN 14214 standards. The results presented in Table V1 showed that all the properties of FSOME meet the requirement of both standard specifications for biodiesel quality. Therefore, trans-esterified FSO could be a viable alternative for petro-diesel.
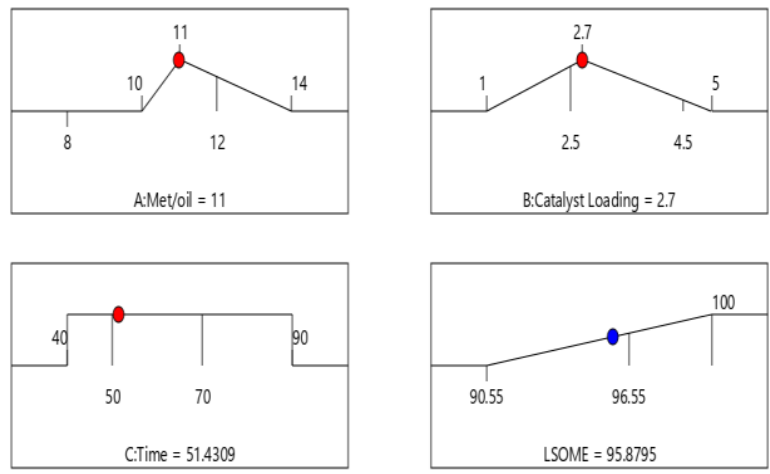

Desirability $=0.815$

Solution 1 out of 18

Fig. 3: Ramp plot of optimized conditions with a desirability performance of $82 \%$
TABLE VI: PHYSICOCHEMICAL PROPERTIES OF UVOME IN COMPARISON WITH ASTM D6751 AND EN D14214

\begin{tabular}{|c|c|c|c|c|}
\hline Property & Units & FSOME & $\begin{array}{l}\text { ASTM } \\
\text { D6751 }\end{array}$ & $\begin{array}{l}\text { EN } \\
1421 \\
4\end{array}$ \\
\hline $\begin{array}{l}\text { Physical } \\
\text { state/colou } \\
\text { r }\end{array}$ & - & $\begin{array}{l}\text { Liquid/ligh } \\
\text { t brown }\end{array}$ & - & - \\
\hline $\begin{array}{l}\text { Density@ } \\
25^{\circ} \mathrm{C}\end{array}$ & $\mathrm{Kg} / \mathrm{m}^{3}$ & 0.8973 & 840 & $\begin{array}{l}0.86- \\
0.90\end{array}$ \\
\hline $\begin{array}{l}\text { Kinematic } \\
\text { Viscosity } \\
\text { @ } 40^{\circ} \mathrm{C}\end{array}$ & $\mathrm{mm}^{2} / \mathrm{s}$ & 2.57 & $\begin{array}{l}1.9- \\
6.0\end{array}$ & $\begin{array}{l}3.5- \\
5.0\end{array}$ \\
\hline Acid Value & $\begin{array}{l}\mathrm{mg} \\
\mathrm{KOH} / \mathrm{g}\end{array}$ & 0.35 & $\begin{array}{l}0.5 \\
\max \end{array}$ & $\begin{array}{l}0.5 \\
\max \end{array}$ \\
\hline FFA & $\%$ & 0.17 & - & - \\
\hline $\begin{array}{l}\text { Iodine } \\
\text { Value }\end{array}$ & $\begin{array}{l}\mathrm{g} \\
\mathrm{I}_{2} / 100\end{array}$ & 60.27 & - & $\begin{array}{l}120 \\
\max \end{array}$ \\
\hline $\begin{array}{l}\text { Calorific } \\
\text { value }\end{array}$ & $\begin{array}{l}\mathrm{g} \\
\mathrm{MJ} / \mathrm{kg}\end{array}$ & 42.91 & - & - \\
\hline $\begin{array}{l}\text { Cetane } \\
\text { number }\end{array}$ & & 62.89 & $47 \mathrm{~min}$ & $\begin{array}{l}51 \\
\min \end{array}$ \\
\hline
\end{tabular}

\section{CONCLUSION}

Biodiesel was successfully produced from flaxseed oil via transesterification method using a bio-alkaline catalyst. The elemental composition of the ash showed that potassium $(\mathrm{K})$ is the main active ingredient responsible for its high activity. RSM was effectively used in the modelling and optimization process of the reaction with the regression coefficient $\left(R^{2}\right)$ of 0.9670 . The four parameters affecting the yield were considered for examining the parametric effects and optimization. The statistical analysis showed that the reaction time is the most significant parameter. To maximise the FSOME yield, the optimal conditions obtained was methanol to oil molar ratio $1: 1$, catalyst loading $2.7 \mathrm{wt} \%$ and reaction time of $51.42 \mathrm{~min}$ at constant temperature of $65{ }^{\circ} \mathrm{C}$. The yield predicted by the RSM under this condition was $95.88 \%$ while the experimental yield was $96.50 \%$ with the difference of less than $1 \%$. The fuel properties of the produced biodiesel from flaxseed oil was also evaluated and compared with the international standards, the result obtained confirms that FSOME is a viable fuel substitute. Therefore, the overall protocol suggest that it can be adopted and scaled up to a sustainable and economical biodiesel production.

\section{REFERENCES}

[1] E. Betiku, A. O. Etim, O. Pereao, and T. V. Ojumu, "Two-Step Conversion of Neem ( Azadirachta indica ) Seed Oil into Fatty Methyl Esters Using a Heterogeneous Biomass-Based Catalyst: An Example of Cocoa Pod Husk," Energy \& Fuels, vol. 31, no. 6, pp. 6182-6193, Jun. 2017. https://doi.org/10.1021/acs.energyfuels.7b00604

[2]B. Changmai, P. Sudarsanam, and L. Rokhum, "Biodiesel production using a renewable mesoporous solid catalyst," Ind. Crops Prod., vol. 145, no. October 2019, p. 111911, 2020. https://doi.org/10.1016/j.indcrop.2019.111911

[3]M. R. Miladinović et al., "Valorization of walnut shell ash as a catalyst for biodiesel production," Renew. Energy, vol. 147, pp. 1033-1043, 2020. https://doi.org/10.1016/j.renene.2019.09.056

[4]J. Ahmad, S. Yusup, A. Bokhari, and R. N. M. Kamil, "Study of fuel properties of rubber seed oil based biodiesel," Energy Convers. Manag., 
vol. 78, pp. 266-275, 2014.

https://doi.org/10.1016/j.enconman.2013.10.056

[5]F. Ullah, A. Bano, and S. Ali, "Optimization of protocol for biodiesel production of linseed (Linum usitatissimum L.) oil," Polish J. Chem. Technol., vol. 15, no. 1, pp. 74-77, 2013. https://doi.org/10.2478/pjct-2013-0013

[6]A. Etim, E. Betiku, S. Ajala, P. Olaniyi, and T. Ojumu, "Potential of Ripe Plantain Fruit Peels as an Ecofriendly Catalyst for Biodiesel Synthesis: Optimization by Artificial Neural Network Integrated with Genetic Algorithm," Sustainability, vol. 10, no. 3, p. 707, Mar. 2018 https://doi.org/10.3390/su10030707

[7]B. Nath, B. Das, P. Kalita, and S. Basumatary, "Waste to value addition: Utilization of waste Brassica nigra plant derived novel green heterogeneous base catalyst for effective synthesis of biodiesel," J. Clean. Prod., vol. 239, p. 118112, 2019. https://doi.org/10.1016/j.jclepro.2019.118112

[8] A. O. Etim, P. Musonge, and A. C. Eloka-Eboka, "Effectiveness of biogenic waste-derived heterogeneous catalysts and feedstock hybridization techniques in biodiesel production," Biofuels, Bioprod. Biorefining, vol. 14, pp. 620-649, 2020. https://doi.org/10.1002/bbb.2094

[9]G. Pathak, D. Das, K. Rajkumari, and L. Rokhum, "Exploiting waste: Towards a sustainable production of biodiesel using: Musa acuminata peel ash as a heterogeneous catalyst," Green Chem., vol. 20, no. 10, pp. 2365-2373, 2018 https://doi.org/10.1039/C8GC00071A

[10] M. Balajii and S. Niju, "A novel biobased heterogeneous catalyst derived from Musa acuminata peduncle for biodiesel production - Process optimization using central composite design," Energy Convers. Manag., vol. 189, no. December 2018, pp. 118-131, Jun. 2019. https://doi.org/10.1016/j.enconman.2019.03.085

[11] M. Gohain, A. Devi, and D. Deka, "Musa balbisiana Colla peel as highly effective renewable heterogeneous base catalyst for biodiesel production," Ind. Crops Prod., vol. 109, no. August, pp. 8-18, Dec. 2017. https://doi.org/10.1016/j.indcrop.2017.08.006

[12] V. O. Odude, A.J. Adesina, O.O. Oyetunde et al., "Application of Agricultural Waste-Based Catalysts to Transesterification of Esterified Palm Kernel Oil into Biodiesel: A Case of Banana Fruit Peel Versus Cocoa Pod Husk," Waste and Biomass Valorization, vol. 10, no. 0123456789, pp. 877-888, 2019. https://doi.org/10.1007/s12649-017-0152-2

[13] K. Rajkumari and L. Rokhum, "A sustainable protocol for production of biodiesel by transesterification of soybean oil using banana trunk ash as a heterogeneous catalyst," Biomass Convers. Biorefinery, 2020 https://doi.org/10.1007/s13399-020-00647-8

[14] E. K. Tetteh and S. Rathilal, "Application of magnetized nanomaterial for textile effluent remediation using response surface methodology," Mater. Today Proc., no. xxxx, 2020. https://doi.org/10.1016/j.matpr.2020.03.827

[15] M. Mohamad, N. Ngadi, S. L. Wong, M. Jusoh, and N. Y. Yahya, "Prediction of biodiesel yield during transesterification process using response surface methodology," Fuel, vol. 190, pp. 104-112, 2017. https://doi.org/10.1016/j.fuel.2016.10.123 